Journal of Materials and Environmental Sciences ISSN : 2028-2508

CODEN : JMESCN

Copyright $\odot$ 2017,

University of Mohammed Premier Oujda Morocco
J. Mater. Environ. Sci., 2018, Volume 9, Issue 1, Page 318-325

https://doi.org/10.26872/jmes.2018.9.1.35

http://www.jmaterenvironsci.com



\title{
Mechanical properties and conductance behavior of fiber glass investigated by different physical methods
}

\author{
Zia Ul Haq ${ }^{1}$, Noor Rehman ${ }^{2 *}$, Azim Khan Khattak ${ }^{1}$, Hidayat Ullah ${ }^{3}$, \\ Farman Ullah Khan ${ }^{1}$, Ali Athar ${ }^{1}$ \\ 1. Institute of Chemical Sciences, Gomal University (29100) Dera Ismail Khan Khyber Pakhtunkhwa, Pakistan \\ 2. Department of Chemistry, Shaheed Benazir Bhutto University (18000) Sheringal, Dir (Upper), Khyber Pakhtunkhwa, \\ Pakistan \\ 3. Institute of Chemical Sciences, University of Peshawar (25000) Khyber Pakhtunkhwa, Pakistan
}

Received 09 Feb 2017,

Revised 04 Jul 2017,

Accepted 09 Jul 2017

Keywords

$\checkmark$ Polymer composites

$\checkmark$ Conductance,

$\checkmark$ Young's modulus,

$\checkmark$ Automatic Vickers,

$\checkmark$ micro hardness testers,

noorrehman@sbbu.edu.pk

Phone: (+92) 3355979230

\begin{abstract}
Fiber glass belongs to polymer metrics composites (PMCs), possessing good resistance to corrosion and oxidation. This work reports stress, strain and young's modulus on fatigue strength of Fiber glass measured by universal testing machine (UTM) method. The results show that the value of stress and young's modulus increases with increasing concentration, while that of strain decreases. Moreover, micro structure analysis, hardness and conductance were measured by automatic Vickers micro hardness testers. As a result, interesting behaviors of these parameters were recorded. The $\mathrm{Ca}(\mathrm{OH})_{2}$ doping significantly increase the conductance of composite material. The highest conductance was observed at 35 wt $\% \mathrm{Ca}(\mathrm{OH})_{2}$ concentration showing conductivity value of $3.98 \times 10^{-4} \mathrm{~S} \mathrm{~cm}^{-1}$. The micro hardness analysis of polymer composite with 35 wt $\% \quad \mathrm{Ca}(\mathrm{OH})_{2}$ concentration showing higher conductance.
\end{abstract}

\section{Introduction}

Glass fibers are most commonly use as a reinforcement material for polymer metrics composites. Their significant and principal advantages are due to the relationship between their low cost, greater tensile strength, high chemical resistance and insulating properties. However, they exhibit some disadvantages like low tensile modulus, high hardness, high specific gravity and low fatigue resistance [1-4]. Fiber glass is a dual phase consists of ferrite ( $\alpha$ Fiber) and austenite ( $\gamma$ Fiber), possesses greater mechanical strength than single phase fiber glass and expected to be used as substitute in various chemical processes. Repeated loading can cause fractures and fatigue failure in fiber glass and elastic strain and plastic deformation cause the crystal structure of fiber glass to dislocate. Therefore it is necessary that the mechanical strength and physical properties should be evaluated in their fatigue state. To study the effects of stress, plastic strain and young's modulus on fatigue strength, a new method for determining plastic strain in composite material using universal testing machine (UTM) methodology has been developed [5] and derived using both these Eshelby's approaches [6] and the Mori-Tanaka theory [7] to express the stress state in composite materials. In this study, copper electrodes and multimeter were used to measure the conductance as well as the dielectric constant tests of the fiber glass specimen. The results showed that the conductance measurements of Polyvinyl alcohol (PVA) polymer composite is enhanced by addition of $\mathrm{Ca}(\mathrm{OH})_{2}$ content. Metallurgical optical microscopy was carried out to study the micro structure analysis of the given polymer composite specimen and the results revealed the comparison between PVA polymer composite specimen and $\mathrm{PVA}+\mathrm{Ca}(\mathrm{OH})_{2}$ composite material. 
1.1 Average Normal Stress: One of the most important aspect of designation related to the deformations occurred due to the loads applied to a member. "The ratio of deformation (Dl) to the length of the rod (l) is termed as strain denoted by "e". The member of constant cross sectional area with length (l), the strain remains constant along the entire member and may be obtained by dividing the total deformation by its length" [8,9].

$$
\sigma=\frac{F}{A}\left[\frac{N}{m^{2}}\right]
$$

Where $E_{X}$ is the strain

Where $E_{t}$ is the strain

$$
E_{x}=\Delta l / l
$$

Where

$$
E_{t}=d l / l
$$

$$
E_{t}=d l / l
$$

1.2 Hooke's Law: "The generalized Hooke's Law can be used to predict the deformations caused in a given material by an arbitrary combination of stresses" as reported in the literature [10]. The linear relationship between stress and strain applies for $0 \leq \sigma \leq 0 \sigma_{\text {yield. }}$



Where: $\quad E$ and $n$ represents the Young's modulus and the Poisson ratio respectively.

$$
E_{z}=-v \frac{\sigma_{x}}{E}-\frac{\sigma_{y}}{E}+\frac{\sigma_{z}}{E}
$$

The Hooke's Law also shows that "strain is possible in the absence of stress. Suppose, if the member is experiencing a load in the y-direction (produces stress in the y-direction). The Law also shows that strain in the $\mathrm{x}$-direction does not equal to zero. The reason is that the material is being pulled outward along the y-direction, the material in the x-direction moves inward to fill in the space until it was occupied, similar to elastic band which becomes thinner as you try to pull away. In this case, the $\mathrm{x}$-direction does not exhibit any external force which acts on them but they show a change in lengthwise. Therefore, it is concluded that strain may exist without stress in the x-direction plane" $[11,12]$. Mathematically the stress can be obtained by dividing the internal forces per unit area as given by following equation $[13,14]$.

\subsection{Nominal or Engineering Strain:}

$$
E_{x}=\Delta l / l
$$

True Strain is given by : 


\subsection{Stress}

Stress may be defined as "the force per unit area- the ratio of applied force $F$ and cross section - defined as force per area". They are of different types

1.4a Tensile stress - "A type of stress that tends to stretch or lengthen the given material - acts normal to the stressed area".

1.4b Compressive stress - "It is a stress that tends to compress or shorten the given material - acts normal to the stressed area".

1.4c Shearing stress - "It is a kind of stress that tends to shear the material - acts in plane to the stressed area at right-angles to tensile stress"

Tensile or Compressive Stress - Normal Stress

Tensile or compressive stress normal to the plane is termed as "normal stress" or "direct stress" and is given by the following equation.

Where

$$
\sigma=F_{n} / A
$$

$\sigma=$ normal stress

$\mathrm{F}_{\mathrm{n}}=$ normal component force

$\mathrm{A}=$ area of cross section

\section{4d Shear Stress}

"Stress that parallel to the plane is normally expressed as "shear stress" and is given by the expression as given below."

$$
\tau=F_{p} / A
$$

Where

$\tau=$ shear stress

$\mathrm{F}_{\mathrm{p}}=$ parallel component force

$\mathrm{A}=$ area of cross section

\subsection{Strain}

Strain may be defined as "deformation of a solid due to stress and is given by the expression below".

$$
\begin{gathered}
\varepsilon=d l / l_{o} \\
=\sigma / E
\end{gathered}
$$

Where

$\mathrm{dl}=$ change of length

$1_{\mathrm{o}}=$ initial length

$\varepsilon=$ unit less measure of engineering strain

$\mathrm{E}=$ Young's modulus

Young's modulus can be used to predict the elongation or compression of an object.

\subsection{Young's Modulus - Modulus of Elasticity (or Tensile Modulus) - Hooke's Law}

Most of the metals distort directly related to the applied load over a range of loads. Stress is proportional to load and strain is proportional to deformation as expressed with Hooke's law.

Where

$$
\begin{aligned}
\mathrm{E} & =\text { stress } / \text { strain } \\
& =\sigma / \varepsilon \\
& =\left(F_{n} / A\right) /\left(d l / l_{o}\right)
\end{aligned}
$$

$\mathrm{E}=$ young's modulus $\left(\mathrm{Nm}^{-2}\right)\left(\mathrm{lbin}^{-2}, \mathrm{psi}\right)$

Modulus of Elasticity, or Young's Modulus, is commonly used for metals and metal alloys and expressed in terms $10^{6} \mathrm{lb}_{\mathrm{f}} \mathrm{in}^{-2}, \mathrm{Nm}^{-2}$ or Pa. Tensile modulus is often used for plastics and is expressed in terms $10^{5} \mathrm{lb}_{\mathrm{f}}$ in $^{-2}$ or GPa".

Shear Modulus 
Shear modulus is given by the relation

$$
\begin{aligned}
& \mathrm{S}=\text { stress } / \text { strain } \\
& =\tau / \gamma \\
& =\left(F_{p} / A\right) /(s / d)
\end{aligned}
$$

Where

$\mathrm{S}=$ shear modulus

$\tau=$ shear stress

$\gamma=$ unit less measure of shear strain

$\mathrm{F}_{\mathrm{p}}=$ force parallel to the faces which they act

$\mathrm{A}=$ area of cross section

$\mathrm{s}=$ displacement of the faces

$\mathrm{d}=$ distance between the faces displaced

\section{Materials and methods}

The different samples of fiber glass sheets were prepared by the standard procedures. Table 1 given below show the variation of the amounts of main constituents in samples. The chopped strand mat sample used was given by its trade name called mat- 450 . The mat was cut into parts having length of $90 \mathrm{~mm}$ and width $25 \mathrm{~mm}$, for each weight of 1 gram.

Table 1: Different samples of glass fibers with varying concentration of PVA.

\begin{tabular}{cccc}
\hline Sample & PVA solution in grams & $\begin{array}{c}\text { Resin and Co/ naphthenate } \\
\text { solution in grams }\end{array}$ & MEKP in grams \\
\hline Sample 1 & 0.6 & 0.20 & 0.10 \\
Sample 2 & 0.7 & 0.23 & 0.13 \\
Sample 3 & 0.8 & 0.26 & 0.13 \\
Sample 4 & 0.9 & 0.30 & 0.15 \\
Sample 5 & 1.0 & 0.33 & 0.16 \\
Sample 6 & 1.1 & 0.36 & 0.18 \\
Sample 7 & 1.2 & 0.40 & 0.20 \\
Sample 8 & 1.4 & 0.46 & 0.23 \\
Sample 9 & 1.5 & 0.50 & 0.25 \\
Sample 10 & 1.6 & 0.53 & 0.27 \\
Sample 11 & 1.7 & 0.56 & 0.28 \\
Sample 12 & 1.8 & 0.60 & 0.30 \\
Sample 13 & 1.9 & 0.63 & 0.32 \\
Sample 14 & 2.0 & 0.66 & 0.33 \\
\hline
\end{tabular}

Once the samples have been prepared, they were allowed to dry in an open atmosphere at room temperature. The samples were than analyzed by Universal testing machine to calculate the various properties of each sample.

\subsection{Specimen preparation}

The surface of the sample was cleaned using acetone and cotton. The sample was prepared by using $5 \mathrm{~g}$ of Polyvinyl Alcohol (PVA) and $1.5 \mathrm{~g}$ of calcium hydroxide $\left(\mathrm{Ca}(\mathrm{OH})_{2}\right.$ using deionized water. The mixture of $\mathrm{PVA}+\mathrm{Ca}(\mathrm{OH})_{2}+$ deionized water was poured into a beaker. The mixture of PVA $+\mathrm{Ca}(\mathrm{OH})_{2}+$ deionized water was stirred with the help of magnetic stirrer. After stirring for some time the sample is poured into mould with the help of funnel. The sample is then dried at room temperature.

The specimens of polymer composite material were analyzed for its structural appearance as well as for its mechanical properties. 


\section{Results and discussion}

\subsection{Tensile tests}

Tensile tests were applied to the samples to obtained data of tensile strength, breaking strength. Analyzing the results of using tensile tests, when the amount of short glass fibers mat is added as reinforcement materials were also increased, like stress, and Young modulus while that of strain was decreased. The results are shown in Figures 1-3. From the Fig. 1 it can be seen that the values of stress to break increased with increasing concentration of the samples. Actually in the fiber reinforced composite material, the reinforcing material is stronger as well as stiffer than the matrix material.

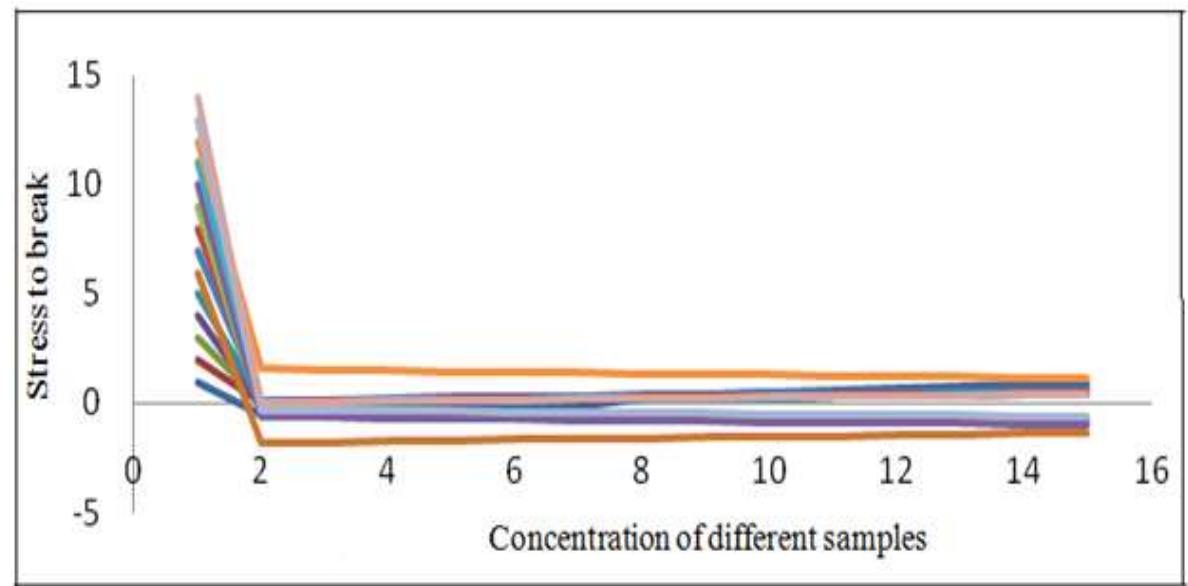

Fig. 1: Stress to break against concentration of different samples.



Fig. 2: Plastic strain to break against concentration of different samples.

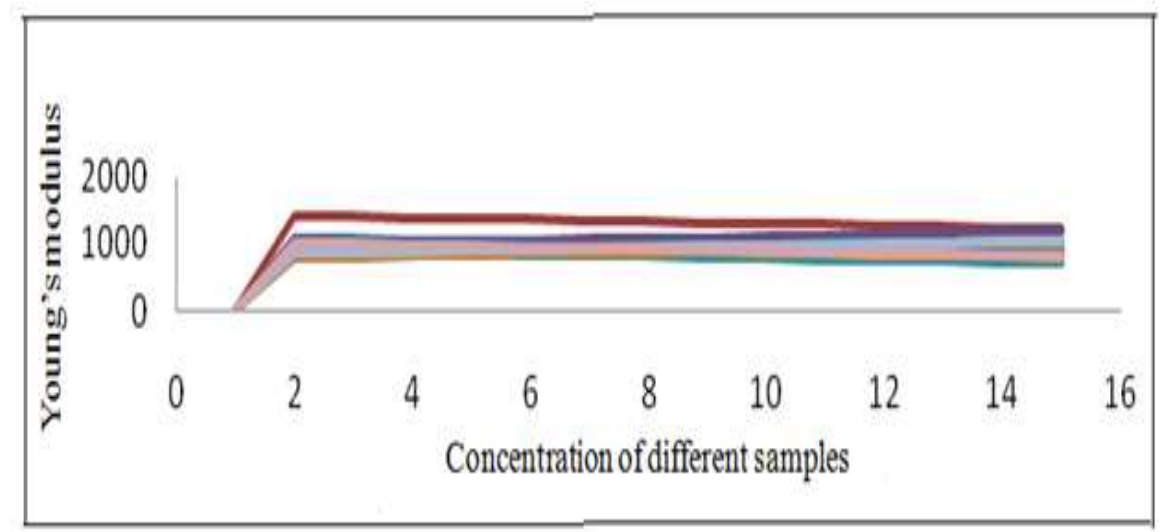

Fig. 3: Young's modulus against concentration of different samples. 


\subsection{Microstructure analysis}

The following Fig. 4 shows the microstructure analysis of $\mathrm{PVA}+\mathrm{Ca}(\mathrm{OH})_{2}$ specimen.



Fig. 4: Structure analysis of $\mathrm{PVA}+\mathrm{Ca}(\mathrm{OH})_{2}$ composite specimen.

The microstructure structure analysis shows the distribution of PVA in matrix. The fiber glass act as reinforcement material that increases the tensile and Young's modulus due to its uniform distribution in the polymer matrix. The analysis also reveals that $\mathrm{Ca}(\mathrm{OH})_{2}$ is evenly distributed throughout the specimen. The figure 4 shows the presence of agglomerates which lower the strain break of fiber glass composite.

\subsection{Electrical conductivity}

The ionic conductance of the poly vinylealcohle based polymer electrolyte film was carried out using digital conductometer [15]. For measuring the ionic conductance (s), using steel electrodes and calculated ionic conductivity values by using the formula given below.

$$
\sigma=\left(G^{*} t\right) / A
$$

Where,

$\sigma=$ Conductivity $\left(\mathrm{S} \mathrm{cm}^{-1}\right)$

$\mathrm{T}=$ Thickness

$\mathrm{R}=$ Bulk resistance

$\mathrm{A}=$ Area of cross section

The ionic conductivity of polymer electrolytes versus composition of $\mathrm{Ca}(\mathrm{OH})_{2}$ at room temperature shown in Fig. 5.The different values are listed in Table 2. As observed in Fig. 5, the ionic conductance increases with the increase in $\mathrm{Ca}(\mathrm{OH})_{2}$ concentration. The highest conductivity of PVA was observed at $3.98 \times 10^{-4} \mathrm{~S} \mathrm{~cm}^{-1}$, when the $\mathrm{Ca}(\mathrm{OH})_{2}$ content was $35 \%$. Similar effect was observed while studying the effect of phosphoric acid on the solid polymer electrolyte [16].

Table 2: Effect of $\mathrm{Ca}(\mathrm{OH})_{2}$ content on the conductivity of polymer electrolyte $\left(\mathrm{PVC}: \mathrm{Ca}(\mathrm{OH})_{2}\right.$ at room temperature.

\begin{tabular}{ccc}
\hline S.No & PVA: $\mathbf{C a}(\mathbf{O H})_{\mathbf{2}} \mathbf{W T} \%$ & Conductivity $\left(\mathbf{S ~ c m}^{-\mathbf{1}}\right)$ \\
\hline 1 & $80: 20$ & $1.45 \times 10^{-6}$ \\
2 & $75: 25$ & $4.96 \times 10^{-5}$ \\
3 & $70: 30$ & $2.09 \times 10^{-4}$ \\
4 & $65: 35$ & $3.98 \times 10^{-4}$ \\
5 & $60: 40$ & $3.37 \times 10^{-4}$ \\
6 & $55: 45$ & $2.79 \times 10^{-4}$ \\
\hline
\end{tabular}




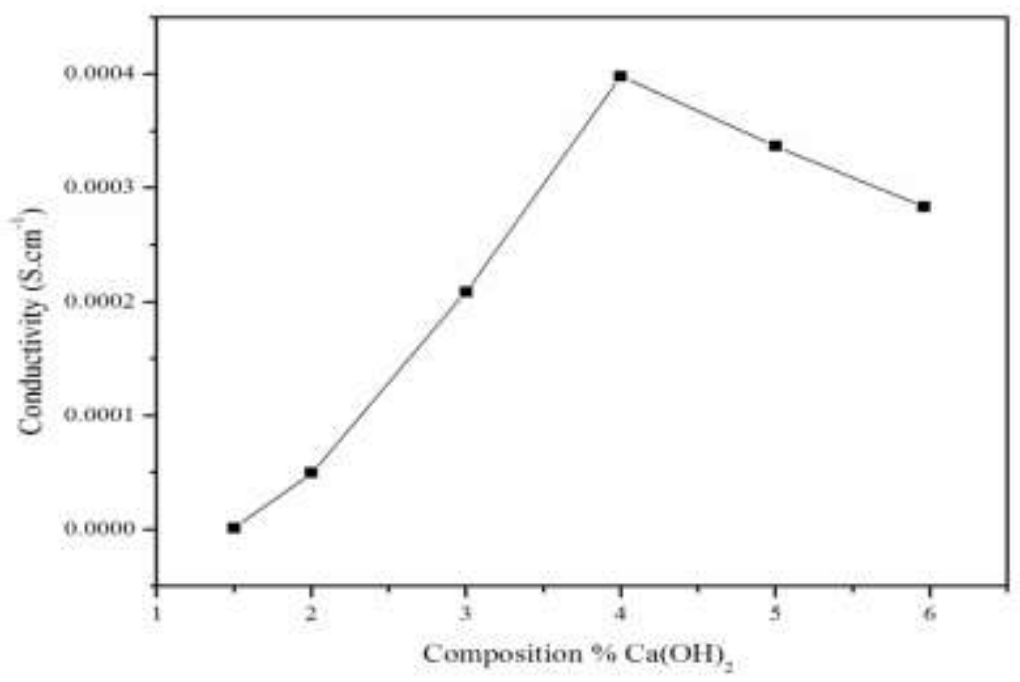

Fig. 5: Effect of $\mathrm{Ca}(\mathrm{OH})_{2}$ content on the conductivity of the polymer electrolyte $\left(\mathrm{PVA}: \mathrm{Ca}(\mathrm{OH})_{2}\right)$ at room temperature

Table 3: Hardness values of polymer composites.

\begin{tabular}{cccccccc}
\hline S.No & $\begin{array}{r}\text { Load } \\
\text { Grams }\end{array}$ & $\begin{array}{r}\text { Load } \\
\mathbf{k g f}\end{array}$ & $\mathbf{d}_{\mathbf{1}}(\mathbf{m m})$ & $\mathbf{d}_{\mathbf{2}}(\mathbf{m m})$ & $\begin{array}{c}\mathbf{d}=\mathbf{d}_{\mathbf{1}}+\mathbf{d}_{\mathbf{2}} \\
\mathbf{2}(\mathbf{m m})\end{array}$ & $\begin{array}{c}\text { Scaling factor } \\
\mathbf{D}=\mathbf{d}^{* \mathbf{0 . 1 1 5 4}}\end{array}$ & $\begin{array}{r}\mathbf{H V = 1 . 8 5 4 F / D 2} \\
\left(\mathbf{N ~ m}^{-1} \mathbf{m}^{-2}\right)\end{array}$ \\
\hline 1 & 100 & 0.981 & 5.6 & 5.7 & 5.65 & 0.65201 & 25.20 \\
2 & 200 & 1.962 & 5.30 & 5.52 & 5.41 & 0.62431 & 51.13 \\
3 & 300 & 2.943 & 4.90 & 5.56 & 5.23 & 0.60354 & 70.24 \\
4 & 400 & 4.905 & 4.50 & 4.54 & 4.52 & 0.57160 & 161.21 \\
\hline
\end{tabular}

\subsection{Micro hardness test}

Micro hardness tests were used to study the resistance of a material to deformation. These tests were carried out on a macroscopic or microscopic level. This is an important relation which permits economically important nondestructive testing of bulk metal deliveries with light weight, even more portable instrument, like automatic Vickers micro hardness testers as given in Table 3. The specimen is pressed with the indenter with a dwell time of 10 to $15 \mathrm{sec}$; all this process was performed using controlled test force. The indenter is removed forming an indent in the sample that appears square shaped.

The actual size of the indent is calculated optically by knowing the two diagonals of the square indent.

The Vickers hardness number is calculated by the test force over the surface cross sectional area of the indent. Taking in to account the average of these two diagonals gives the Vickers hardness.

(i) The assembly is automatically controlled by applying and removing the load.

(ii) The Fig 4 below shows the specimen placed on the anvil that has a screw treaded base.

For the loading of $0.98,1.962 .943$ and $4.905 \mathrm{kgf}$, the hardness number was calculated in the range of 25.20 to161.21. At a load of $4.905 \mathrm{kgf}$, the hardness number abruptly increased to 161.21 as given in the above table 2. This showed that the critical indentation load was $4.905 \mathrm{kgf}$. Moreover, the hardness of the specimens used in this study increases with the increasing test load, while others has reported the tendency of hardness of materials decreases with the increasing test load.

\section{Conclusions}

The conductance of polymer composite material shows the enhancement by $\mathrm{Ca}(\mathrm{OH})_{2}$ doping. The high value of conductance was observed at $35 \mathrm{wt} \% \mathrm{Ca}(\mathrm{OH})_{2}$ concentration with conductance of $3.98 \times 10^{-4} \mathrm{~S} \mathrm{~cm}^{-1}$. The micro hardness test of polymer composite specimen at $35 \mathrm{wt} \% \mathrm{Ca}(\mathrm{OH})_{2}$ concentration showing maximum conductivity. For load of $0.98,1.962 .943$ and $4.905 \mathrm{kgf}$, the hardness number was in the range of 25.20 to 161.21. At a $4.905 \mathrm{kgf}$ load, the hardness number suddenly increased to 161.21 . This indicated that the critical indentation load was $4.905 \mathrm{kgf}$. Metallurgical microscope was used for the micro-structural analysis of polymer 
composite specimen. The structural feature of $\mathrm{PVA}+\mathrm{Ca}(\mathrm{OH})_{2}$ composite revels that $\mathrm{Ca}(\mathrm{OH})_{2}$ is evenly distributed throughout the specimen.

From the observed mechanical properties, it was seen that the values of stress increased while that of strain was decreased. The stress to strain is called the efficiency of the work and is also known as the young's modulus, which were observed to increase due to the addition of fibers contents indicating the increase in efficiency.

Acknowledgments- The authors are thankful to Higher Education Commission (HEC) Pakistan, Shaheed Benazir Bhutto University and Gomal University D.I. Khan for providing facilities to complete this research project. I am also thankful to Mr. Hidayat Ullah for helpful discussions as well as for the collaboration in this research project.

\section{References}

1. P. K. Mallick (1997) Fiber Reinforced Composites. Materials, Manufacturing and Design; Marcel Dekker Inc.: New York, NY, USA.

2. W. D. Callister (2003) Materials Science and Engineering, an Introduction, 6th ed.; John Wiley \& Sons: Hoboken, NJ, USA.

3. D. Hull, T. W. Clyne, (1996) An Introduction to Composite Materials, 2nd ed.; Cambridge University Press: Cambridge, UK.

4. M. Etcheverry, S. E. Barbosa, Materials. 5 (2012) 1084-1113.

5. T. Sasaki, Z. Lin, Y. Hirose, Transaction of JSME (Series A). 606 (1997) 370-377.

6. J. D. Eshelby, Proc. R. Soc. London A 241 (1957) 376-396.

7. T. Mori, K. Tanaka, Acta Materilia, 21 (1973) 571-574.

8. C. Arulappan, A. Duraisamy, D. Adhikari, S. Gururaja, J. Reinf. Plast. Comp. 34 (2015) 3-18.

9. M. Karahan, A. Jabbar, N. Karahan, J. Reinf. Plast. Comp. 34 (2015) 37-48.

10. I. Medeiros, M. Gomes, J. Oral. Sci. 49 (2007) 61-66.

11. T. Agarwal, K. A. Gupta, S, Alam, Int. J. Comp. Mat. 2 (2012) 7-21.

12. S. K. Tripathi, A. Gupta, M. Kumara, Bull. Mat. Sci. 35 (2012) 969-975.

13. S. Rajendran, R. S. Babu, R. M. Uusha, Bull. Mater. Sci. Indian Academy of Sciences. 34 (2011) 1525-1530.

14. F. Hussain, M. Hojjati, M. Okamoto, An Overview. J. Comp. Mat. 40 (2006) 1511-1575.

15. V. Tavman, I. Çeçe, A. Özdemir, Arch. Mat. Sci. Eng. 40 (2009) 84-88.

16. L. Sa'adu, M. A. Hashim, M. bin Baharuddin, J. Mat. Sci. Res. 3 (2014) 48-58.

(2018) ; http://www.jmaterenvironsci.com 